\title{
Morphology and molecules support the new monotypic genus Fenghwaia (Rhamnaceae) from south China
}

\author{
Gang-Tao Wang ${ }^{1,2}$, Jiang-Ping Shu ${ }^{1,2}$, Guo-Bin Jiang ${ }^{1,2}$, \\ Yu-Qiang Chen ${ }^{3}$, Rui-Jiang Wang'
}

I Key Laboratory of Plant Resources Conservation and Sustainable Utilization, South China Botanical Garden, Chinese Academy of Sciences, Guangzhou, Guangdong 510650, China 2 University of Chinese Academy of Sciences, Beijing 100049, China 3 Taicheng Town, Taishan, Jiangmen City, Guangdong 529200, China

Corresponding author: Rui-Jiang Wang (wangrj@scbg.ac.cn)

Academic editor: H. Schaefer | Received 5 August 2020 | Accepted 14 December 2020 | Published 6 January 2021

Citation: Wang G-T, Shu J-P, Jiang G-B, Chen Y-Q, Wang R-J (2021) Morphology and molecules support the new monotypic genus Fenghwaia (Rhamnaceae) from south China. PhytoKeys 171: 25-35. https://doi.org/10.3897/ phytokeys. 171.57277

\begin{abstract}
Fenghwaia, a new monotypic genus, along with the new species Fenghwaia gardeniicarpa, is described from Guangdong Province, China. The combined features of inferior ovary, cylindrical drupaceous fruits and orbicular and dorsiventrally-compressed seeds with an elongate and pronounced basal appendage make the new genus significantly different from other genera of the family. In addition, its pollen morphology also showed great similarity to other species of this stenopalynous family. The molecular phylogenetic analysis, based on nuclear ribosomal internal transcribed spacer (ITS) and plastid trnL-F intron spacer (trnL-F) DNA sequence data from the new genus and the other 375 species representing 58 genera of Rhamnaceae, indicates that Fenghwaia is nested within the 'rhamnoid' group and sister to the tribe Rhamneae and then both sister to the tribe Maesopsideae. A taxonomic classification key to the 'rhamnoid' group is provided, based on morphological characters. A global conservation assessment is also performed and classifies Fenghwaia gardeniicarpa as Near Threatened (NT).
\end{abstract}

\section{Keywords}

Fenghwaia, IUCN, palynology, Rhamnoid, taxonomy

Copyright Gang-Tao Wang et al. This is an open access article distributed under the terms of the Creative Commons Attribution License (CC BY 4.0), which permits unrestricted use, distribution, and reproduction in any medium, provided the original author and source are credited. 


\section{Introduction}

The buckthorns (Rhamnaceae Juss.) are a cosmopolitan family of small trees, shrubs, climbers and, occasionally, herbs and are well represented both in tropical and temperate regions (Raven and Axelrod 1974). This family includes approximately 900 species belonging to about 60 genera and 11 tribes. China hosts 13 genera and 137 species, distributed throughout the whole country, but mostly in south and southwest China (Chen and Schirarend 2007). The species of the family are mainly characterised by having basically cymose inflorescence mostly in the axillary position, usually $4-5$-merous flowers, superior to inferior 2-4-loculed ovary with one ovule in each locule and indehiscent schizocarpic or capsular fruits (Medan and Schirarend 2004).

Rhamnaceae was recently revealed to be a monophyletic family and a member of the order Rosales with other eight families, viz. Rosaceae, Barbeyaceae, Dirachmaceae, Elaeagnaceae, Ulmaceae, Cannabaceae, Moraceae and Urticaceae on the basis of molecular evidence (APG IV 2016). The systematic treatment of Rhamnaceae, based on molecular data, morphological, anatomical and geographical information, indicated that Rhamnaceae should divided into three groups, viz. the 'rhamnoid' group, 'ziziphoid' group and the 'ampelozizyphoid' group (Richardson et al. 2000a, 2004; Hauenschild et al. 2016b).

During our field investigation in 2018, a treelet of Rhamnaceae, morphologically similar to Sageretia species, but bearing cylindrical and more or less fleshy drupaceous fruits with an inferior ovary and persistent calyxes, somewhat similar to the capsules of Gardenia, was found along the riverside of a secondary broad-leaf forest adjacent to a reservoir in Taishan, Jiangmen City, Guangdong Province. This plant is very different from any known species and evoked great interest for clarifying the taxonomic name and its phylogenetic relationship. Several field expeditions from March to August 2019 were subsequently undertaken to clarify its inflorescence and flower characters. Phylogenetic analysis, based on ITS and trnL-F, along with morphological comparisons, suggested that this species is best treated as a new taxon belonging to a new genus of Rhamnaceae.

\section{Material and methods}

All morphological data of the new species were collected by Light Microscope and Stereomicroscope. Palynological observations followed Guo and Wang (2011). The voucher specimens have been deposited at South China Botanical Garden, Chinese Academy of Sciences (IBSC).

Since nuclear ribosomal internal transcribed spacer region (ITS) and plastid trnL-F intron spacer region $(t r n L-F)$ were already shown to include sufficient information to reconstruct well-supported topologies in Rhamnaceae (Hauenschild et al. 2016a, b), hence a total of five genomic DNAs were extracted from five different individuals, using a modified cetyltrimethylammonium bromide (CTAB) method (Allen et al. 2006).

The primers and PCR protocols were outlined by Hauenschild et al. (2016a, b). The PCR products were sent to Sangon Biotech (Shanghai, China) and sequencing 
was conducted using an ABI 3730xl DNA Analyzer (Applied Biosystems, Invitrogen, Foster City, CA, USA).

Multiple locus alignment of 590 operational taxonomic units (OTUs) was performed by Mafft v 7.453 (Katoh et al. 2002) with default parameters and ambiguous positions in the alignment were removed by GBlocks $v 0.91 \mathrm{~b}$ with the parameters $(-\mathrm{b} 4=5,-\mathrm{b} 5=\mathrm{h})($ Castresana 2000). After filtering, the best-fit model $(\mathrm{TIM}+\mathrm{F}+\mathrm{R} 4)$ was selected on the basis of the Bayesian Information Criterion (BIC) using Modelfinder (Kalyaanamoorthy et al. 2017) and the phylogenetic tree with the Maximum Likelihood (ML) method was performed by IQ-TREE v1.6.12 (Nguyen et al. 2015). Ultrafast bootstrap values were calculated with 1000 random replicates (Hoang et al. 2018). For Bayesian Inference (BI), we used the GTR+G+I model and performed four independent Markov Chain Monte Carlo (MCMC) reactions in MrBayes v3.2.6 (Ronquist and Huelsenbeck 2003), running five million generations every Markov Chain, sampling one tree every 1,000 generations, rejecting 25\% of the trees as burn-in after the value of average standard deviation of split frequencies was lower than 0.01 .

\section{Results}

All DNA data of 585 OTUs, representing 375 species of 58 genera and 11 Rhamnaceae tribes, released by Hauenschild et al. (2016a), were downloaded from GenBank and merged into our present analysis. The GenBank numbers of the newly-sequenced Fenghwaia gardeniicarpa are: Y.Q.Chen \& G.T. Wang 1223-1, ITS: MN795061, trnL-F: MN793985; Y.Q. Chen \& G.T. Wang 1223-2, ITS: MN795062, trnL-F: MN793986; Y.Q. Chen \& G.T. Wang 1224-1, ITS: MN795063, trnL-F: MN793987; Y.Q. Chen \& G.T. Wang 1224-2, ITS: MN795064, trnL-F: MN793988; Y.Q. Chen \& G.T. Wang 1225, ITS: MN795065, trnL-F: MN793989.

The topology of our phylogenetic tree is similar to that of Hauenschild et al. (2016b), but the tribe Paliureae, defined by Hauenschild et al. (2016b) with very weak support, collapsed in our analysis, because of the exclusion of Hovenia and Sarcomphalus. The new genus Fenghwaia is nested into the 'rhamnoid' group and sister to the tribe Rhamneae with weak bootstrap support $(\mathrm{BS} / \mathrm{PP}=75 / 0.55)$, but then both sister to the tribe Maesopsideae with strong support $(\mathrm{BS} / \mathrm{PP}=100 / 1)$ (Fig. 1).

\section{Taxonomic description}

\section{Fenghwaia G.T. Wang \& R.J. Wang, gen. nov.}

urn:Isid:ipni.org:names:77213613-1

Type species. Fenghwaia gardeniicarpa G.T. Wang \& R.J. Wang.

Diagnosis. Fenghwaia is distinctly different from other genera by a character combination of its cucullate flowering petals, inferior ovary with 3-locular and one ovule in each locule, elongate capsular fruit with five longitudinal ridges and verrucose seeds. 


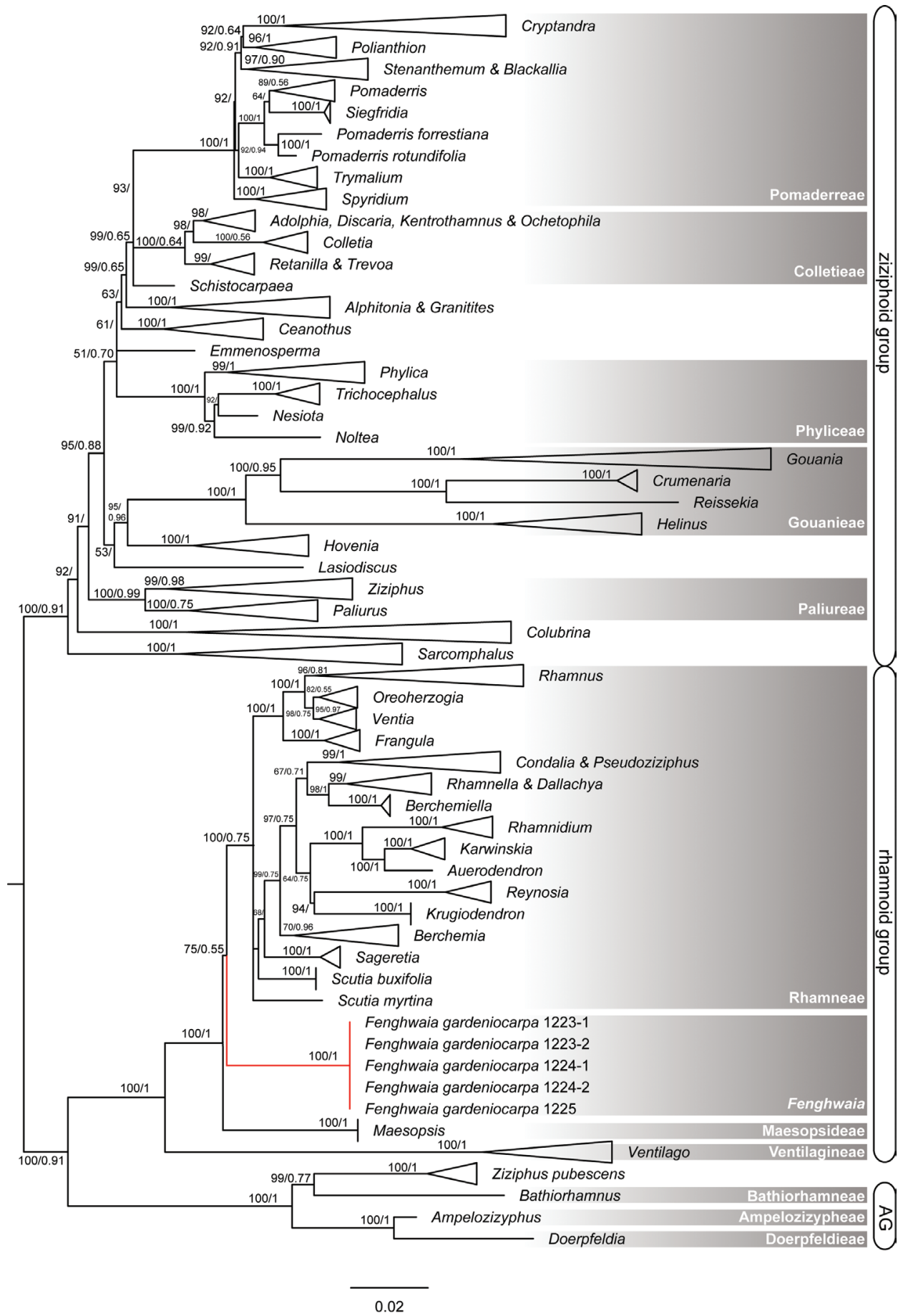

Figure I. The phylogenetic consensus tree of Rhamnaceae with ML and BI methods, on the basis of ITS and trnL-F sequences. AG: 'ampelozizyphoid' group. The numbers above the branches are Maximum Likelihood support values (left) and MrBayes posterior probability (right). 
A single species is only known from China.

Etymology. We dedicate this new genus to Professor Chen Fenghwai, a Chinese plant taxonomist, in honour of his great contribution to the botanical gardens in China.

\section{Fenghwaia gardeniicarpa G.T. Wang \& R.J. Wang, sp. nov. urn:Isid:ipni.org:names:77213614-1}

Fig. 2

Type. China. Guangdong Province, Jiangmen City, Taishan, Mt. Nanfengshan, under secondary mixed forests, $22^{\circ} 11^{\prime} \mathrm{N}, 112^{\circ} 56^{\prime} \mathrm{E}$, elev. ca. $410 \mathrm{~m}, 6$ July 2019, R.J. Wang, G.T. Wang \& G.B. Jiang 1228 (bolotype: IBSC0849961; isotypes: CSH0171170; IBK00421260; IBSC0849962; IBSC0849963; KUN1347949; PE02251842).

Description. Treelet, evergreen, 0.5-2 m tall, slender, much branched at top; main stems dark or brown, slender, glabrous; young branches rusty strigose at surface. Leaves alternate, anisophyllous, often clustering at the top of branches; petiole 2-5 mm long, pubescent; leaf blade 5.5-10.1 × 1.9-4.0 cm, elliptic, oblanceolate-elliptic or ovate, thinly leathery, glabrous both sides, acuminate to caudate at apex, cuneate at base; secondary veins 3-5 each side, mid-rib and secondary veins smooth adaxially and prominent abaxially; margin entire at base and then serrate to apex. Inflorescence in sessile or shortly peduncled, axillary cymes or small thyrses, 3-5-flowered; bracts ca. 0.5-1.0 mm long, lanceolate to broadly triangular, yellow to rusty. Flowers bisexual, actinomorphic, yellowish-green, ca. 4-5 $\mathrm{mm}$ in diameter; pedicels very short to $4-6 \mathrm{~mm}$ long, glabrous; calyx lobes five, $2.0-3.0 \times \mathrm{ca}$. $1.5 \mathrm{~mm}$, ovate triangular, depressed longitudinally at middle; hypanthium $2-3 \mathrm{~mm}$ long, slightly campanulate; petals five, ca. $1.5 \mathrm{~mm}$ long, cucullate, each partly covering the pollen-presenting surface of the anthers, shortly clawed at base, concaved at apex; stamens five, antepetalous, ca. $1.3 \mathrm{~mm}$ long, enclosed by petals; anthers ca. $0.3 \mathrm{~mm}$ long, ovoid, 4-locular, dorsifixed, filaments ca. $1.0 \mathrm{~mm}$ long; disc inconspicuous, adnate to the lower part of hypanthium; styles ca. $1.5 \mathrm{~mm}$ long, stigma 3-lobed; ovary inferior, 3-1ocular, with one ovule in each locule, ovules anatropous, basal, erect. Fruit drupaceous, more or less fleshy, cylindrical, ca. $1.5 \mathrm{~cm}$ long, $0.4-$ $0.6 \mathrm{~cm}$ in diam., with five longitudinal ridges on surface, slowly dehiscent at top and then septicidally, glabrous; calyx lobes persistent. Seeds ca. $4 \times 3 \mathrm{~mm}$, orbicular, dorsiventrally compressed, brown, verrucose at surface, with an elongate and pronounced basal appendage.

Phenology. Flowering from June to October; fruiting from August to December.

Palynology. The pollen grains of the new species are monads, isopolar, suboblate, radially symmetrical, angulaperturate, 3-zono-colporate apertures and psilate to perforate tectum. The pollen size is $14.9(13.3-17.1) \times 21.5(16.1-21.1) \mu \mathrm{m}$ and P/E value is 0.86 (Fig. 3). 


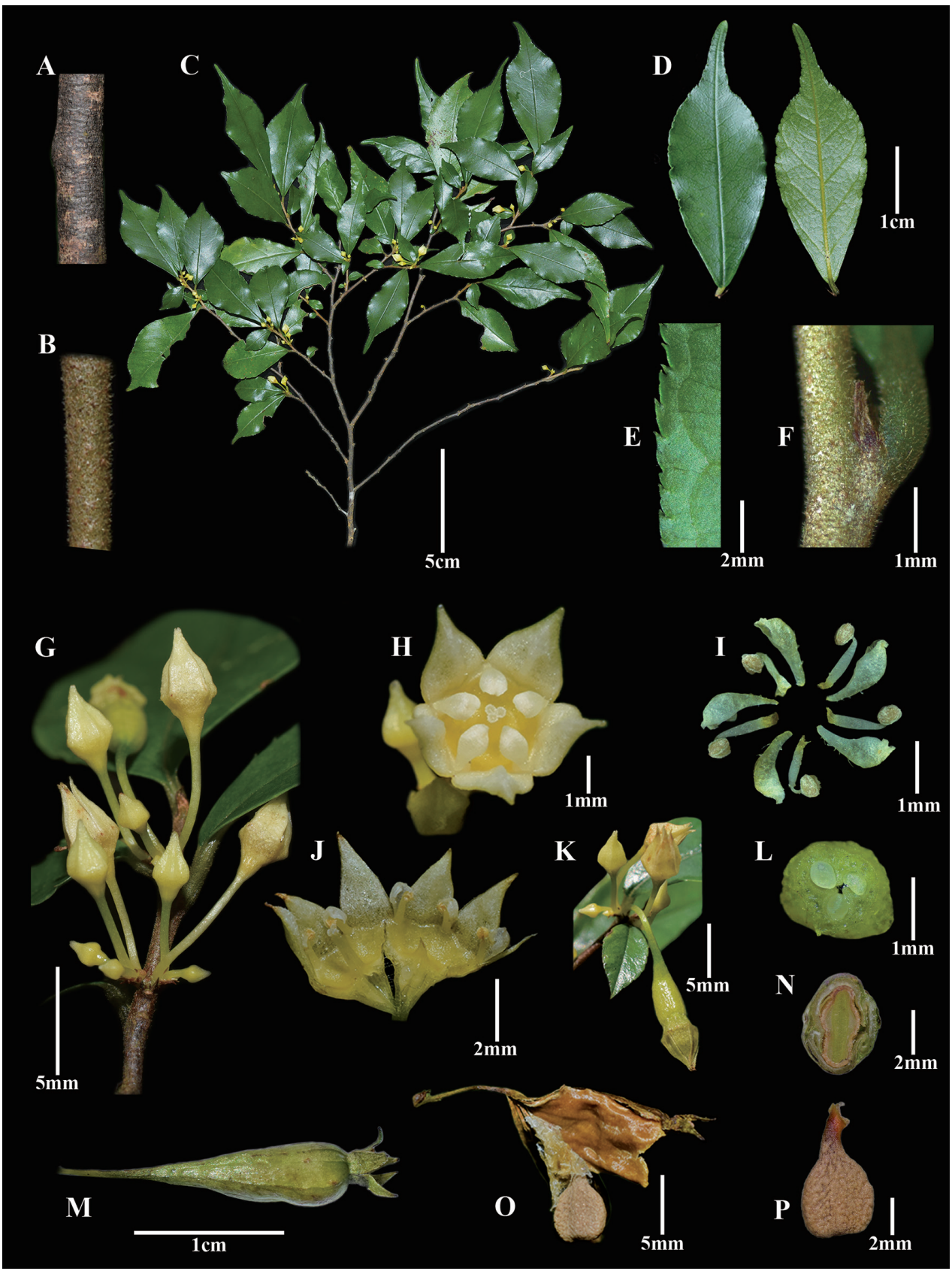

Figure 2. Fenghwaia gardeniicarpa: A main stem with glabrous surface $\mathbf{B}$ young stem with pubescent surface $\mathbf{C}$ fertile branches $\mathbf{D}$ adaxial (left) and abaxial (right) side of leaf blade, respectively $\mathbf{E}$ serrated leaf margin $\mathbf{F}$ stipule $\mathbf{G}$ inflorescence $\mathbf{H}$ flower in anthesis $\mathbf{I}$ morphology of petals and stamens $\mathbf{J}$ longitudinal section of a flower, showing the stamens enclosed by cucullate petals $\mathbf{K}$ young fruit $\mathbf{L}$ transection section of an ovary, showing three ovules $\mathbf{M}$ mature fruit $\mathbf{N}$ transection section of mature fruit with only one well-developed seed $\mathbf{O}$ dehiscent capsule $\mathbf{P}$ seed, with an elongate and pronounced basal appendage. Photos: G.T. Wang, G.B. Jiang. 

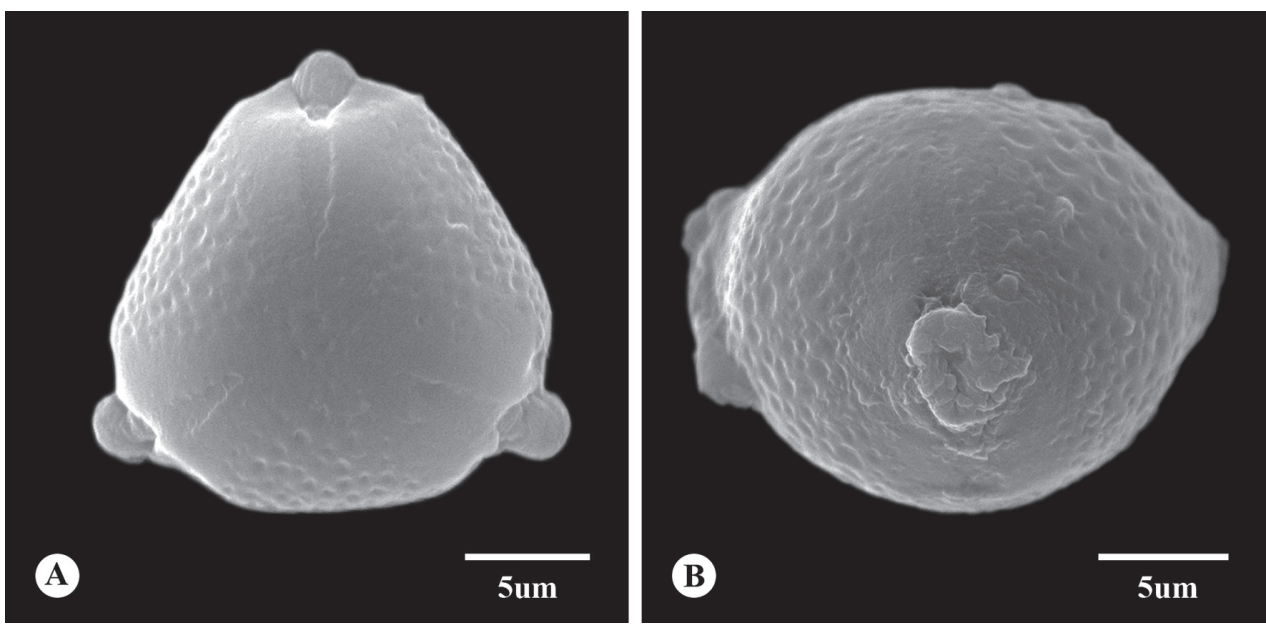

Figure 3. Pollen grains of Fenghwaia gardeniicarpa: A polar view B equatorial view.

Distribution and habitat. Fenghwaia gardeniicarpa is endemic to mountains in Jiangmen District, Guangdong Province, China. It grows under secondary mixed forests at altitudes of 230-450 m, mountain slopes with 60-70\% canopy density, accompanying herbal Gahnia tristis Nees (Cyperaceae) and Adiantum flabellulatum L. (Adiantaceae) and woody Barthea barthei (Hance ex Benth.) Krasser (Melastomataceae), Dunnia sinensis Tutcher (Rubiaceae) and Illicium dunnianum Tutcher (Schisandraceae).

Preliminary conservation assessment. About 2000 mature Fenghwaia gardeniicarpa individuals from four localities have been found in less than $800 \mathrm{~km}^{2}$ up to now. This area can be classified as the extent of occurrence. The plants have no any ornamental or medicinal uses. They are well protected in a Nature Reserve and the population is not severely fragmented. In addition, no population decline and no extreme fluctuations caused by natural events have been observed in their habitats. According to the International Union for Conservation of Nature (2012) and IUCN Standards and Petitions Committee (2019), a category of Near Threatened (NT) is recommended for Fenghwaia gardeniicarpa for the present.

Etymology. The species name highlights the striking resemblance with fruits of Gardenia jasminoides Ellis (Rubiaceae), an unusual and new feature for a fruit of Rhamnaceae.

Vernacular name. Feng Huai Mu (Chinese pronunciation); 封怀木 (Chinese name).

Paratypes. China: Guangdong Province, Jiangmen City, Taishan, Chixi Town, Tonggu Village, $21^{\circ} 55^{\prime} \mathrm{N}, 112^{\circ} 56^{\prime} \mathrm{E}$, elev. $440 \mathrm{~m}, 2$ June 2019, Y.Q. Chen \& G.T. Wang 1223, 1224, 1225, 1226 (IBSC!); Guangdong Province, Jiangmen City, Taishan, Chixi Town, Luobo Village, $21^{\circ} 55^{\prime} \mathrm{N}, 112^{\circ} 55^{\prime} \mathrm{E}$, elev. $107 \mathrm{~m}, 20$ June 2020, R.J. Wang \& Y.Y. Liu 5928 (IBSC!); Guangdong Province, Jiangmen City, Xinhui, Gudoushan Nature Reserve, 22 ${ }^{\circ} 9^{\prime} \mathrm{N}, 112^{\circ} 55^{\prime} \mathrm{E}$, elev. $231 \mathrm{~m}, 3$ October 2019, H.G. Ye et al. GDS-00849 (IBSC!). 


\section{Discussion}

\section{Palynology of Fenghwaia gardeniicarpa}

Rhamnaceae is a stenopalynous family (Erdtman 1952). The pollen morphology of the Rhamnaceae usually has suboblate to oblate spheroidal or subprolate, a distinct triangular shape in polar view, oblate shape in equatorial view and 3-zonocolporate features. It does not show any special features and the descriptions usually concur with each other (Punt et al. 2003). The tectum of Rhamnaceae can be microreticulate, striate or rugulate to reticulate, baculate, verrucate, psilate, with more or less densely-spaced perforations and this variation of exine ornamentation has usually been used for classifying the pollen type (Schirarend and Köhler 1993; Medan and Schirarend 2004; Perveen and Qaiser 2005). In general, the main features of pollen grains of Fenghwaia gardeniicarpa are consistent with those of most other Rhamnaceae species with respect to the shape, polarity, symmetry, aperture number and position, size and tectum ornamentation (Medan and Schirarend 2004). However, the exine ornamentation of Fenghwaia gardeniicarpa is more similar to that of the tribe Rhamneae, as observed in Berchemia (reticulate), Frangula, Rhamnus (suprareticulate-rugulate, psilate), Sageratia (fossulate-perforate) than to that of the Maesopsistype (baculate) (Punt et al. 2003; Perveen and Qaiser 2005; Naimat et al. 2012).

\section{Phylogenetic relationship of Fenghwaia}

Based on a phylogenetic analysis of $r b c L$ and $t r n L-F$ sequences of the plastid genome, Richardson et al. (2000b) outlined a new tribal classification of Rhamnaceae, recognising 11 tribes encompassing the informally-named groups of 'rhamnoid', 'ampeloziziphoid' and 'ziziphoid'. Our phylogenetic analysis showed that Fenghwaia is nested within the 'rhamnoid' group. Thus, the 'rhamnoid' group consists of the tribes of Rhamneae, Maesopsideae and Ventilagineae and the genus Fenghwaid. The weak support $(\mathrm{ML}=75 / \mathrm{BI}=0.55)$ of the clade Rhamneae/Fenghwaia was probably caused by lack of adequate informative sites in the applied fragments. For example, only trnL-F sequences of Maesopsis eminii were applied in the present analysis. Morphologically, Rhamneae can be easily recognised by its fleshy fruit and 2- or 4-locular ovary. Maesopsideae and Ventilagineae have superior or half inferior ovaries, 1-2-locular, drupe (tribe Maesopsideae), samara or rostrate capsules (tribe Ventilagineae). Moreover, Maesopsis differs from all other genera in Rhamnaceae in its single-celled ovary and a style laterally attached to the fruit, rather than apically. Ventilagineae is unique in its fruits with a pronounced apical appendage (Richardson et al. 2000b).

Fenghwaia has an inferior and 3-loculed ovary, orbicular and dorsiventrally compressed seeds with an elongate and pronounced basal appendage, but its morphological characters are obviously different from those of other taxa in the 'rhamnoid' group. In addition, the genera that have an inferior ovary and 3-locular in Rhamnaceae are all in the ziziphoid group, viz. Phylica, Trichocephalus and Nesiota of the tribe Phyliceae, 
all genera of the tribe Gouanieae, Siegfriedia, Spyridium and Cryptandra of the tribe Pomaderreae, and Alphitonia and Granitites of the undefined tribe.

\section{A taxonomic classification key of the 'rhamnoid' group}

1 Ovary inferior, 3-locular; fruits dry, cylindrical, with ridges on the surface.... Fenghwaia

- Ovary superior, half-inferior or rarely inferior 1, 2-or 4-locular; fruits with wings, dry membranous rings or fleshy 2

$2 \quad$ Fruit an apically-winged samara or a rostrate capsule Ventilagineae

- $\quad$ Fruit a 1-4-locular drupe, not samara or a rostrate capsule 3

3 Ovary superior or half-inferior, 2- or 4-locular Rhamneae

- Ovary superior, 1-locular Maesopsideae

\section{Acknowledgements}

We are grateful to Professor HU Chi-Ming and Professor XIA Nian-He for their valuable nomenclature recommendation, Mr. YANG Yi for his constructive suggestions during the draft preparation.

The work was supported by the Guangdong Provincial Science \& Technology Program (No. 2018B030320004) and the National Wild Plant Germplasm Resource Center for South China Botanical Garden, Chinese Academy of Sciences (ZWGX1905).

\section{References}

Allen G, Flores-Vergara M, Krasnyanski S, Kumar S, Thompson WF (2006) A modified protocol for rapid DNA isolation from plant tissues using cetyltrimethylammonium bromide. Nature Protocols 1(5): 2320-2325. https://doi.org/10.1038/nprot.2006.384

APG IV (2016) An update of the Angiosperm Phylogeny Group classification for the orders and families of flowering plants: APG IV. Botanical Journal of the Linnean Society 181(1): 1-20. https://doi.org/10.1111/boj.12385

Castresana J (2000) Selection of conserved blocks from multiple alignments for their use in phylogenetic analysis. Molecular Biology and Evolution 17(4): 540-552. https://doi. org/10.1093/oxfordjournals.molbev.a026334

Chen YL, Schirarend C (2007) Rhamnaceae. In: Wu ZY, Raven PH, Hong DY (Eds) Flora of China (Vol. 12). Science Press, Beijing \& Missouri Botanical Garden Press, St. Louis, 115-168.

Erdtman G (1952) Pollen morphology and plant taxonomy. Angiosperms. Chronica Botanica Co., Waltham, 539 pp.

Guo X, Wang RJ (2011) Hedyotis xinyiensis (Rubiaceae), a new species from China. Annales Botanici Fennici 48(5): 443-447. https://doi.org/10.5735/085.048.0510 
Hauenschild F, Favre A, Salazar GA, Muellner-Riehl AN (2016a) Analysis of the cosmopolitan buckthorn genera Frangula and Rhamnus s.l. supports the description of a new genus, Ventia. Taxon 65(1): 65-78. https://doi.org/10.12705/651.5

Hauenschild F, Matuszak S, Muellner-Riehl AN, Favre A (2016b) Phylogenetic relationships within the cosmopolitan buckthorn family (Rhamnaceae) support the resurrection of Sarcomphalus and the description of Pseudoziziphus gen. nov. Taxon 65(1): 47-64. https:// doi.org/10.12705/651.4

Hoang DT, Chernomor O, Haeseler VA, Minh BQ, Vinh LS (2018) UFBoot2: Improving the ultrafast bootstrap approximation. Molecular Biology and Evolution 35(2): 518-522. https://doi.org/10.1093/molbev/msx281

International Union for Conservation of Nature (2012) IUCN Red List Categories and Criteria: version 3.1, ed 2. Gland, Switzerland and Cambridge, UK.

IUCN Standards and Petitions Committee (2019) Guidelines for using the IUCN Red List Categories and Criteria. Version 14. http://www.iucnredlist.org/documents/RedListGuidelines.pdf

Kalyaanamoorthy S, Minh BQ, Wong TKF, Haeseler VA, Jermiin LS (2017) ModelFinder: Fast model selection for accurate phylogenetic estimates. Nature Methods 14(6): 587-589. https://doi.org/10.1038/nmeth.4285

Katoh K, Misawa K, Kuma K, Miyata T (2002) MAFFT: A novel method for rapid multiple sequence alignment based on fast Fourier transform. Nucleic Acids Research 30(14): 3059-3066. https://doi.org/10.1093/nar/gkf436

Medan D, Schirarend C (2004) Rhamnaceae. In: Kubitzki K (Ed.) The families and genera of vascular plants (Vol. 6). Springer, Heidelberg, 320-338. https://doi.org/10.1007/978-3662-07257-8_37

Naimat R, Khan MA, Khan KY, Ali B, Zahidullah, Mazari P (2012) Palynomorphological characterization of some speceis of selected genera of family Rhamnaceae. Research in Plant Biology 2(3): 4-9.

Nguyen L, Schmidt HA, Haeseler VA, Minh BQ (2015) IQ-TREE: A fast and effective stochastic algorithm for estimating maximum likelihood phylogenies. Molecular Biology and Evolution 32(1): 268-274. https://doi.org/10.1093/molbev/msu300

Perveen A, Qaiser M (2005) Pollen flora of Pakistan-XLIV. Rhamnaceae. Pakistan Journal of Botany 37(2): 195-202.

Punt W, Marks A, Hoen PP (2003) The Northwest European Pollen Flora, 63 Rhamnaceae. Review of Palaeobotany and Palynology 123(1-2): 57-66. https://doi.org/10.1016/ S0034-6667(02)00154-9

Raven PH, Axelrod DI (1974) Angiosperm biogeography and past continental movements. Annals of the Missouri Botanical Garden 61(3): 539-673. https://doi.org/10.2307/2395021

Richardson JE, Fay MF, Cronk QCB, Bowman D, Chase MW (2000a) A phylogenetic analysis of Rhamnaceae using $r b c L$ and $\operatorname{trn} L-F$ plastid DNA sequences. American Journal of Botany 87(9): 1309-1324. https://doi.org/10.2307/2656724

Richardson JE, Fay MF, Cronk QCB, Chase MW (2000b) A revision of the tribal classification of Rhamnaceae. Kew Bulletin 55(2): 311-340. https://doi.org/10.2307/4115645 
Richardson JE, Chatrou LW, Mols JB, Erkens RHJ, Pirie MD (2004) Historical biogeography of two cosmopolitan families of flowering plants: Annonaceae and Rhamnaceae. Philosophical Transactions of the Royal Society of London - Series B, Biological Sciences 359(1450): 1495-1508. https://doi.org/10.1098/rstb.2004.1537

Ronquist F, Huelsenbeck JP (2003) MrBayes 3: Bayesian phylogenetic inference under mixed models. Bioinformatics (Oxford, England) 19(12): 1572-1574. https://doi.org/10.1093/ bioinformatics/btg180

Schirarend C, Köhler E (1993) Rhamnaceae Juss. World Pollen and Spore Flora 17(18): 1-53. 